\title{
Children's Motor Skill and Intervention: What Have We Known?
}

\author{
Syafruddin $^{1 *}$, Syahrial Bakhtiar ${ }^{1}$, Ruri Famelia $^{1}$ \\ ${ }^{1}$ Faculty of Sports Sciences, Universitas Negeri Padang,Prof. Dr.Hamka, Padang, Indonesia \\ ${ }^{*}$ Corresponding author. Email: syafruddin fikunp@yahoo.com
}

\begin{abstract}
Fundamental motor skills (FMS) are the basic pattern of movements to support more complex movement in sports and daily activities. One might argue that FMS is naturally emerged along with body development. However, research has shown that FMS should be taught appropriately to children. However, we have not known yet how effective the intervention to improve children's FMS and what factors influence children FMS development during intervention. The aim of this study is to review some intervention on children FMS. Data was selected from Pubmed, PsycInfo, SportDiscus and ERIC. It was found that structured and developmental appropriate motor skill program would effectively improve children FMS. Family contexts, children perceived motor competence and physical activity are factors that influence children to improve their motor competence. This study is beneficial to set a standard for designing an appropriate intervention for Indonesian children.
\end{abstract}

\section{Keywords: Children, Motor Skill}

\section{INTRODUCTION}

Fundamental motor skills are the basic pattern of movements to support more complex movement in sports and daily activities. Research has shown the essential of fundamental motor skills for children in relation to be physically active throughout their life. In his model of fundamental and sport-related phases, children should be able to improve their fundamental motor skills when they are 2-7 years old. However, motor skills cannot emerge naturally in children. They should be taught appropriately to children. This reason brings out a thought that an appropriate motor skill program should be design to provide a proper experience for children to improve their motor skills. In order to create an appropriate motor skill intervention, it is important to examine children's motor competence to get a description about children's characteristics. Different region may have different characters of children. Furthermore, knowing factors that influence children motor skills is another key step to develop a good motor skill program, either at schools or community programs. Because of those reasons, much research has studied the description of children's motor competence, various approach in motor skill intervention and factors that influence children's motor competence. Therefore, the purpose of this paper is to examine the methods behind how studies were collected. The next purpose is to summarize the findings of studies and identify implications for future research or practice.

\section{METHODOLOGY}

Searches were conducted using single and combined terms. Then, articles were selected by the following inclusion criteria: (1) young children (preschool, kindergarten and elementary schools students), (2) quantitative, qualitative and single subject, (3) Typically developing and developmental delay, (4) original data, and (5) precision in measurement dependent variable. The articles were excluded based on these criteria: (1) children over 9 years, and (2) children with disability (autism, ADHD, Learning disabilities, intellectual disabilities).

\section{RESULTS AND DISCUSSION}

Some researchers have identified children's motor skill generally in some areas and ethnicities. Pope, Liu, \& Getchel (2011) conducted a study to obtain a baseline data of object control skills for 111 Hispanic children who enrolled in Head Start preschool in Texas, US. 61 boys and 50 girls with age between 38 to 52 months administered a Test of Gross Motor Development-2 (TGMD-2) object control skills. Pope and colleagues found that Hispanic children living in poverty are delayed in object control skills. Found no gender differences in children's object control skills[1]. It might be due to the floor effects in their skills since the majority of children had poor and very poor standard score in their assessment. These findings inspired other researchers to assess children's motor skill in another part of the world.

Motor skills of 330 preschoolers (171 boys and 159 girls) in the Sydney area of New South Wales (NSW), Australia [2]. By using TGMD-2, they concluded that 
most children were developmentally delayed in their motor skills. Running was the most proficiency skills among Australian children while striking was the least proficiency skills. Moreover, there were no gender differences in both locomotor and object control skills, however, girls tended higher in locomotor skills and boys higher in object control skills. Who suggested that boys are significantly better in object control than girls. This discrepancy may be in consequence of live coding process during TGMD-2 assessment. It is likely to be bias when researchers do live coding instead of video coding in TGMD-2 assessment[3].

Studies in both US and Australia provide enough evidences that children, mostly, have motor developmental delays without learning motor skills during childhood. However, these evidences are not enough to create a good motor skill program for children. It needs to be supported by key factors that influence children's motor skills. Thus, it seems important to summarize findings about the relationship of children's motor skills with other variables. The association among children's fundamental motor skills and others factors

Fundamental motor skills develop during childhood. In this period, children receive many factors that influence themselves in determining what they want to do. Furthermore, their decision during this period would determine their habit and behavior throughout their life. That is why it is important to evaluate some factors that affect children's motor development and the consequence of that relationship. Those relationships can be examined by correlational studies, in which this study evaluates factors that contribute to particular variable. It is not causality studies. Overall, findings from some studies depict that family contexts, habitual physical activity, perceived motor competence, child welfare services and physical fitness are associated with children's motor skills.

Investigated 846 children (471 boys, 375 girls) age 4-6 years and their family to find out the relationship between family contexts and children's fundamental motor skills [4]. They found that motor skill performance positively associated with parental education, father's physical activity, transport to school by bicycle, and the high value placed by parents high on sport-specific aspects of children's physical activity. This finding shows that the father is more influenced to children than mother in term of physical activity. It might be related to cultural believe that man is more representative for exercise than women. Then, this belief seems also influence children thought about doing exercise. Another interesting finding from this study is the transportation to go to school, which using bicycle is related to children's motivation in being physically active. On the other hand, children's fundamental motor skills negatively associated with father-child interaction in TV-viewing and reading books, the high importance placed by parents on winning and performance in children's physical activity. In this case, the habit of interaction while watching TV or reading books position children to be sedentary, which controvert with being physically active. Parent's demands for children to win games or sports would tend to give negative thought about doing physical activity, resulting the decline in fundamental motor skills. Results from this study convey how important parents', especially father's role in building an active habit for children.

Considering children's habitual physical activity related to fundamental motor skills, two different studies [5], [6]. Both groups of researchers looked the relationship between physical activity and fundamental motor skills of children in the different direction. Evaluated 394 of 3.6 5.0 year old children in Scotland to examine whether children habitual physical activity contributes to fundamental motor skills[5]. They claimed that there were significant but weak cross-sectional relationships between habitual physical activity (specifically time spent in moderate to vigorous physical activity and total physical activity) and fundamental movement skills in modern preschool children. In contrast, the opposite direction of relationship between children's motor competence and physical activity among 198 preschoolers in South Carolina, US [6]. They concluded that motor competence defined the participation of 4-year-old children in physical activity but, not for 3-year-old children. These findings are supported by Synergistic Model of Motor Competence and Physical Activity during early childhood, physical activity drives children to improve their motor competence, while during middle childhood and adolescence, motor competence affects children's physical activity [7]. It is understood that more physical activity provides more chance to practice and sharp their motor skills. convey that it is true that motor competence drive 4 year old children's physical activities, this finding slightly deviate from Synergistic Model of Motor Competence and Physical Activity because 4 year old children are still considered as early childhood[6]. It may be due to the different sample size between 3 year old and 4 year old children, which are 80 and 118 consecutively. Theoretically, middle childhood and adolescence are significantly influenced by motor competence to participate in physical activity because higher motor competence arouses children's perception in motor competence, called perceived motor competence.

a research with 119 Head Start preschoolers to find the relationship between perceived motor competence and fundamental motor skill in preschool children. She found that there was a moderate significant correlation between perceived motor competence and fundamental motor skills, in which this correlation significantly higher for boys than girls [3]. This finding is along with Synergistic Model of Motor Competence and Physical Activity visualized that perceive motor competence mediated children motor competence and physical activity [7]. Higher perceived motor competence would drive children motor competence and physical activity for young children.

\section{Motor skill intervention}

Considering all profile of children's fundamental motor skills and factors associated with them, researcher have designed some motor skill intervention with different approaches. Direct instructional (a.k.a low autonomy) and 
mastery motivational climate (a.k.a high autonomy) are two approaches that are implemented in school settings, including in preschools and kindergarten. A direct instructional approach is based on performance orientation and the teacher is the center of activity, while a mastery instructional approach is based on effort orientation and the student is the center of the activity.

Some researchers have found some evidences about both approaches. a direct instructional approach intervention, which combined motor skill and nutrition lessons, called NutriActive, to 70 children[8]. They found that children improve their motor skills and some variables in physical fitness. compared mastery motivational and direct instructional approach and claimed that both approach significantly promoted children's motor skill, however, mastery motivational approach improved and retained children's perceived motor competence than direct instructional[9]. Even, direct instructional approach decreased children's perception about their motor skills after nine weeks of post- intervention. Viewed from physiology aspects, [10], [11] claimed that mastery motivational approach improved children physical activity heart rate, yet, there was no significant different in cortisol level in children between free play activity group and mastery motivational group [11]. It implies that the enjoyment that mastery motivational approach offers is not enough to stimulate the decline in stressful of children. Alternatively, it may be due to the sensitivity of saliva essay for examining of cortisol level for children.

\section{CONCLUSIONS}

Overall, findings from scientific studies prove motor competence would drive children to be engaged with physical activity more active. Thus, children need to be taught by appropriate motor skill program with various approaches to promote their motor competence. Also, it is important to note that family contexts, children perceived motor competence and physical activity are factors that influence children to improve their motor competence. Further it would promote their physical fitness. Hence, future research would be beneficial to produce good motor skill programs for children.

\section{REFERENCES}

[1] Pope, M. L., Liu, T., \& Getchell, N. "Object-control skills in Hispanic preschool children enrolled in Head Start. Perceptual and Motor Skills". 112, 1, Feb 2011. pp. 193-200.

[2] Hardy, L. L., King, L., Farrell, L., Macniven, R., \& Howlett, S. "Fundamental movement skills among Australian preschool children". Journal of Science and Medicine in Sport, 13, 5, Sept 2010, pp. 503508.

[3] Robinson, L. E. "The relationship between perceived physical competence and fundamental motor skills in preschool children". Child: Care, Health and Development, 37, 4, Dec 2010, pp 589-96.

[4] Cools, W., De, M. K., Samaey, C., \& Andries, C. "Fundamental movement skill performance of preschool children in relation to family context". Journal of Sports Sciences, 29, 7, March 2011, pp. 649-60.

[5] Fisher, A., Reilly, J. J., Kelly, L. A., Montgomery, C., Williamson, A., Paton, J. Y., \& Grant, S. "Fundamental movement skills and habitual physical activity in young children". Medicine and Science in Sports and Exercise, 37, 4, April 2005, pp. 684-688.

[6] Williams, H. G., Pfeiffer, K. A., O'Neill, J. R., Dowda, M., McIver, K. L., Brown, W. H., \& Pate, R. R. "Motor skill performance and physical activity in preschool children". Obesity (silver Spring, Md.), 16, 6, Feb 2008, pp. 6.

[7] Gallahue, D., Ozmun, J.C., and Goodway,J.D. "Understanding Motor Development: Infants, Children, Adolescents, Adults (7th ed.)". New York: McGraw-Hill Companies, Inc. Jann 2012, pp. 25.

[8] Matvienko, O., \& Ahrabi-Fard, I "The effects of a 4-week after-school program on motor skills and fitness of kindergarten and first-grade students". American Journal of Health Promotion: Ajhp, 24, 5. May 2010, pp. 58.

[9] Robinson, L. E., Rudisill, M. E., \& Goodway, J. D. "Instructional climates in preschool children who are at-risk. Part II: perceived physical competence". Research Quarterly for Exercise and Sport, 80(3). Jan 2013, pp. 543-551.

[10] Parish, L. E., Rudisill, M. E., \& St. Onge, P. "Mastery motivational climate: Influence on physical play and heart rate in African American toddlers". Research Quarterly for Exercise and Sport, 78(3). Jan 2013, 171-178.

[11] Wall, S. J., Rudisill, M. E., \& Gladden, L. B. "Cortisol Response to Physical Activity in African American Toddlers Attending Full-Time Day Care". Research Quarterly for Exercise and Sport, 80(4), Jan 2013, pp. 739-746. 